University of Nebraska - Lincoln

DigitalCommons@University of Nebraska - Lincoln

$1-11-2007$

\title{
Return to the wild: Translocation as a tool in conservation of the Desert Tortoise (Gopherus agassizii)
}

\author{
Kimberleigh J. Field \\ University of Nevada - Reno, kimberleigh_field@fws.gov \\ C. Richard Tracy \\ University of Nevada - Reno, dtracy@biodiversity.unr.edu \\ Philip A. Medica \\ Western Ecological Research Center, pmedica@usgs.gov \\ Ronald W. Marlow \\ University of Nevada - Reno, marlowhoff@aol.com \\ Paul Stephen Corn \\ Aldo Leopold Wilderness Research Institute, steve_corn@usgs.gov
}

Follow this and additional works at: https://digitalcommons.unl.edu/usgsstaffpub

Part of the Earth Sciences Commons

Field, Kimberleigh J.; Tracy, C. Richard; Medica, Philip A.; Marlow, Ronald W.; and Corn, Paul Stephen, "Return to the wild: Translocation as a tool in conservation of the Desert Tortoise (Gopherus agassizii)" (2007). USGS Staff -- Published Research. 93.

https://digitalcommons.unl.edu/usgsstaffpub/93

This Article is brought to you for free and open access by the US Geological Survey at DigitalCommons@University of Nebraska - Lincoln. It has been accepted for inclusion in USGS Staff -- Published Research by an authorized administrator of DigitalCommons@University of Nebraska - Lincoln. 


\title{
Return to the wild: Translocation as a tool in conservation of the Desert Tortoise (Gopherus agassizii) is
}

\author{
Kimberleigh J. Field ${ }^{a, *}$, C. Richard Tracy ${ }^{a}$, Philip A. Medica ${ }^{b}$, Ronald W. Marlow ${ }^{a}$, \\ Paul Stephen Corn ${ }^{c}$ \\ ${ }^{a}$ Biological Resources Research Center/MS 314, University of Nevada - Reno, Reno, NV 89557, USA \\ ${ }^{\mathrm{b}}$ US Geological Survey, Western Ecological Research Center, 160 N. Stephanie Street, Henderson, NV 89074, USA \\ ${ }^{\mathrm{c}}$ US Geological Survey, Aldo Leopold Wilderness Research Institute, 790 E. Beckwith Avenue, Missoula, MT 59801, USA
}

\section{A R T I C L E I N F O}

Article history:

Received 31 May 2006

Received in revised form

16 November 2006

Accepted 27 November 2006

Available online 11 January 2007

Keywords:

Augmentation

Chelonian

Mojave Desert

Nevada

Relocation

Supplementation

\begin{abstract}
A B S T R A C T
Translocation could be used as a tool in conservation of the threatened Mojave Desert Tortoise (Gopherus agassizii) by moving individuals from harm's way and into areas where they could contribute to conservation of the species. Numerous factors may affect the success of translocations, including the conditions experienced by tortoises in holding facilities while awaiting translocation. The tortoises available for our translocation study had been provided supplemental water during their years spent in a captive holding facility, potentially inducing carelessness in water conservation. In addition to generally investigating the efficacy of translocation, we compared the effects of continuing with the effects of ceasing the holding facility's water supplementation regimen. After exposure to one of the two water regimens, all tortoises were given the opportunity to hydrate immediately prior to release. We examined behavior, body mass, carapace length, movement, and mortality of tortoises for two activity seasons following release to the wild. Water supplementation was correlated with high rates of carapace growth and distant movements by males after release. Lengthy movements following translocation may be problematic for conservation planning, but this should be evaluated in light of the goals and circumstances of each translocation project. Although the mortality rate was $21.4 \%$ in 1997 , data suggest that drought conditions at the site rather than the translocation itself negatively affected the tortoises. None of the tortoises died during their second season at the site. Our results indicate that translocation should be considered a useful tool in conservation of the Desert Tortoise.
\end{abstract}

(c) 2006 Elsevier Ltd. All rights reserved.

\section{Introduction}

Translocations of animals or intentional releases to the wild as attempts to establish, reestablish, or augment populations (Griffith et al., 1989) have been used with a number of species with varying levels of success. One review of translocation programs for reptiles and amphibians reported that only 19\% were successful (Dodd and Seigel, 1991). Success rates may be higher, however, when programs of indeterminate success are eliminated from the calculation (Burke, 1991).

\footnotetext{
is Information on obtaining unpublished reports and documents cited in this paper may be requested by contacting the US Fish and Wildlife Service's Desert Tortoise Recovery Office in Reno, NV, USA.

* Corresponding author: Present address: US Fish and Wildlife Service, Nevada Fish and Wildlife Office, 1340 Financial Blvd., Suite 234, Reno, NV 89502, USA. Tel.: +1 775861 6300; fax: +1 7758616301.

E-mail addresses: kimberleigh_field@fws.gov (K.J. Field), dtracy@biodiversity.unr.edu (C.R. Tracy), pmedica@usgs.gov (P.A. Medica), marlowhoff@aol.com (R.W. Marlow), steve_corn@usgs.gov (P.S. Corn). 0006-3207/\$ - see front matter @ 2006 Elsevier Ltd. All rights reserved. doi:10.1016/j.biocon.2006.11.022 This article is a U.S. government work, and is not subject to copyright in the United States.
} 
Definitions of success are variable and determining ultimate success can require lengthy studies (Fischer and Lindenmayer, 2000; Seigel and Dodd, 2002). Translocation may be a useful tool in conservation of some species, yet well designed studies are necessary to properly evaluate its efficacy.

The Mojave population of the Desert Tortoise (Gopherus agassizii) that occurs north and west of the Colorado River in the United States is protected as a threatened species under the federal Endangered Species Act (USFWS, 1990). The recovery plan associated with this federal listing included guidelines for experimental translocations (USFWS, 1994). In Las Vegas, Nevada, many Desert Tortoises were maintained in captivity at the Desert Tortoise Conservation Center (DTCC) after their removal from land undergoing urban development. We viewed experimental translocations as opportunities to test whether tortoises otherwise destined for lifetimes in captivity could be used to contribute to the recovery of the species. Some biologists have cautioned against releasing formerly captive animals because they may represent sources of disease, stress, and/or unplanned gene flow to wild tortoise populations (Berry, 1972, 1975; St. Amant and Hoover, 1978; Berry, 1986; Bury et al., 1988; Dodd and Seigel, 1991; Jacobson et al., 1991). Previous translocation studies suggested that formerly captive Desert Tortoises may not be competent in foraging or finding suitable shelter in the wild and short-term survival rates ranged from $0 \%$ to $100 \%$ for various cohorts (Berry, 1974; Cook et al., 1978; Cook, 1983). These studies did not provide sufficient evidence to support or contest the efficacy of translocation as a tool in conservation of the Desert Tortoise.

Captive and free-ranging Desert Tortoises differ considerably in their access to and use of water. Infrequent and unpredictable rainfall in the Mojave Desert allows wild tortoises few opportunities to drink, whereas tortoises at the DTCC receive provisions of water daily throughout their active seasons. Tortoises at the DTCC anticipate activation of the sprinklers and drink frequently (Ruby et al., 1994; Charles LaBar, personal communication). In addition, captive tortoises may not drink after rainstorms (Minnich, 1977) and some frequently void dilute urine (Robert Espinoza, personal communication). Retention of bladder water is important in that it can be reabsorbed for regulation of bodily solute levels (Dantzler and SchmidtNielson, 1966; Minnich, 1977) and hydration of dry plant matter in the gut (Peterson, 1996b). Captive tortoises conditioned to plentiful drinking water and no need to be conservative in retaining bladder water may experience functional drought conditions upon release to the wild. Although Desert Tortoises are able to cope with temporary imbalances in water budget (Nagy and Medica, 1986; Peterson, 1996a), tolerate high plasma osmolalities (Dantzler and Schmidt-Nielson, 1966; Minnich, 1977; Peterson, 1996a), and have low rates of water loss (Schmidt-Nielsen and Bentley, 1966; Naegle, 1976; Tracy, 1982; Nagy and Medica, 1986; Peterson, 1996a), mortality or morbidity caused by dehydration can be prevalent in drought years. During a drought in 1990, eight of nine deaths among a sample of 22 tortoises monitored in California were attributed to dehydration and related starvation (Peterson, 1994). We were concerned that the tortoises at the DTCC may have become too negligent about water conservation to do well in the wild, and we were interested in testing the effects of discon- tinuing water supplementation prior to release. In this study, we generally investigated the efficacy of translocation and tested the hypothesis that ending the supplementation of water in the fall prior to the spring release would increase initial success in translocation as measured through changes in body mass, changes in carapace length, behavior, movements, and mortality of translocated tortoises. This initial period began at time of release in spring and went up to the second period of winter inactivity following release. We refer to the periods of activity between hibernation events as activity seasons, thus from release to first hibernation is the first season and from end of first hibernation through beginning of second hibernation is the second season in the wild.

\section{Materials and methods}

\subsection{Study subjects}

We used 32 adult Desert Tortoises that had been maintained in outdoor pens at the DTCC for $7 \mathrm{yr}$ and 10 juveniles that had been at the DTCC for $2 \mathrm{yr}$. All experimental tortoises were classified as negative on ELISA tests for antibodies to Mycoplasma spp. This reduced the chances of translocating tortoises infected with the pathogen Mycoplasma agassizii, which has been implicated as a cause of Upper Respiratory Tract Disease (URTD) (Brown et al., 1994). At the DTCC, tortoises received water daily throughout their active seasons until they entered hibernacula in fall 1996. Tortoises were removed from their pens on 25 and 26 March 1997, before many individuals had emerged from hibernacula and prior to the time that water was provisioned for that season. Adult experimental tortoises were $200-274 \mathrm{~mm}$ in carapace length with body masses of 1308-3401 g. Juvenile carapace lengths were 125-165 mm and body masses 334-603 g. On 27 March, the experimental tortoises were given the opportunity to drink for $30 \mathrm{~min}$. After their body masses were recorded (Acculab Z6000 electronic balance), tortoises were placed in burrows inside randomly assigned experimental pens. Four males, four females, and two or three juveniles were released into each pen. Minimum time spent in the pens under experimental conditions was 27 days with some tortoises remaining in pens to up to 57 days. Each tortoise was fitted with a radio transmitter (AVM models G3, SB2, or SB2-RL for adults; SM1-H for juveniles) and was marked by notching the marginal scutes (Cagle, 1939) and by attaching a small numbered tag (of paper) to the carapace with epoxy. Transmitter attachment added $<5 \%$ to the body mass of any animal.

\subsection{Experimental pens}

Tortoises were housed in four pens $(15.2 \mathrm{~m} \times 15.2 \mathrm{~m})$ as the precondition before translocation. The pens had fiberglass walls $(0.8 \mathrm{~m})$ and water sprinklers. Two pens received water daily from 07:45 to 08:00 h (local time) beginning 28 March 1997. Three terracotta saucers were placed beneath the sprinkler's spray to collect water for the tortoises to drink. Tortoises from these pens are referred to as watersupplemented (WS). Two pens received no water, and those 
tortoises are referred to as not supplemented (NS). In each pen, three artificial burrows were constructed of polyvinyl chloride (PVC) pipes (1.22 $\mathrm{m}$ long and $38.1 \mathrm{~cm}$ diameter) cut in half lengthwise and buried at a downward angle in the soil. Two additional pieces of PVC pipe (30 cm diameter), cut in the same fashion as above, were laid on the ground as additional cover sites. The pens had comparable numbers of native shrubs. Tortoises ate dried alfalfa and slightly moistened iguana chow pellets (Zeigler Bros. Inc. $20 \%$ protein, $1 / 8$ in. pellets, no. 53-6406-18-39) in keeping with the DTCC's feeding schedule.

\subsection{Translocation site}

The $90 \mathrm{~km}^{2}$ translocation site, hereafter referred to as the Large-Scale Translocation Study (LSTS) site, was located in southern Nevada (WGS 84 Zone 11: 647,000 m E 3,953,000 m N). The north (bordered by Nevada Highway 161), south, and east (bordered by Interstate Highway 15) sides of the site had tortoise-proof fencing, and the unfenced western border was formed by the Spring Mountains. The resident, wild tortoise density was approximately 15-20 tortoises $/ \mathrm{km}^{2}$ (USFWS, unpublished) in a Mojave Desert scrub plant community dominated by the creosote bush (Larrea tridentata) and white bursage (Ambrosia dumosa) association (Turner, 1982). Climate of the site was typical for the northeastern Mojave Desert with approximately $97 \mathrm{~mm}$ of annual precipitation (occurring in summer and winter) and temperatures ranging from the mean January minimum of $-0.1^{\circ} \mathrm{C}$ to the mean July maximum of $40.1^{\circ} \mathrm{C}$ (Rowlands, 1995).

The release area was located approximately $32 \mathrm{~km}$ southwest of the DTCC. Tortoise density in the release area was likely depressed due to mortality by motor vehicles on Interstate Highway 15 prior to installation of fencing for this translocation project (Hoff and Marlow, 2002). We dug 13 burrows (0.3 $\mathrm{m}$ long, spaced $19-49 \mathrm{~m}$ apart) with a power auger and shovels in the central-eastern section of the LSTS site. We did not plan to release more than 6 tortoises a day (limited by observer availability), yet wanted enough burrows available in the event that some tortoises occupied these burrows subsequent to their days of release. Burrows were labeled with metal tags, and their Universal Transverse Mercator (UTM) coordinates were measured using a Global Positioning System (GPS) unit. These burrows served as the starting points of released tortoises.

An automated weather station and four rain gauges on site measured rainfall. Additional rainfall data were obtained from the Jean Airport ( $7 \mathrm{~km}$ from release area, $<0.5 \mathrm{~km}$ from northeastern border of LSTS site) and McCarran International Airport (approximately $45 \mathrm{~km}$ northeast of the LSTS site).

\subsection{Release}

Tortoises were placed in plastic tubs and transported by truck to the LSTS site ( $48 \mathrm{~km}$ by road). So that water supplementation regimen (to address potential careless voiding of bladder water after release) would be a variable, rather than time since last drink, all tortoises were given access to about $3 \mathrm{~cm}$ of water in their tubs for $20 \mathrm{~min}$ prior to release. Body masses before and after this procedure as well as observations of drinking and/or voiding were recorded. Tortoises were released by placing them headfirst into burrows. Twenty-eight tortoises were released from 23 April to 23 May 1997. Releases took place between 08:00 and 09:57 h, when air temperatures ranged from 21.5 to $30.0^{\circ} \mathrm{C}$. Six females, eight males, and one juvenile from the WS group were released, while seven females, five males, and one juvenile from the NS group were released (Table 1). High ambient temperatures prevented releases 6-19 May and prohibited release of the remaining 14 tortoises.

Each tortoise's behavior was observed for approximately $4 \mathrm{~h}$ on the days of release. Observers recorded items ingested and marked the paths traveled by the tortoises with flagging, so that the actual distances moved by tortoises could be calculated.

\subsection{Body mass and carapace length}

Body masses were measured using a Pesola spring scale in 1997 and an Ohaus electronic balance (model CT 6000) in 1998. Straight-line carapace lengths were measured with slide calipers (Haglof Inc., Sweden). Body mass and carapace length were recorded on day of release, 15 days after release, and once a month thereafter.

\subsection{Animal movements}

Tortoises were located up to twice weekly using a handheld receiver (Telonics) and antenna through July in 1997, except when radio signals were lost temporarily. Tortoises were tracked once each month from August 1997 to April 1998 and once each week from May 1998 to November 1998. Data recorded each time a tortoise was located included UTM coordinates, descriptive location, behavior, and condition of the animal.

\subsection{Analyses}

Data were checked for homogeneity of variance using BrownForsythe tests and for normality using Kolmogorov-Smirnov tests. Analyses of covariance were used to analyze change in body mass of WS and NS tortoises while in experimental pens and on the day of release with body mass at time of placement into experimental pens as the covariate. Repeated measures analyses of variance (ANOVA) were used to analyze changes in body mass after day of release, with sex and treatment as factors, and tortoise movements, with sex by treatment group as a factor. Home range sizes were calculated and mapped in ArcView ${ }^{\mathrm{TM}}$ (ESRI, Redlands, CA, USA) with the animal movement extension (Hooge and Eichenlaub, 1997) using the minimum convex polygon method. Mean home range sizes were compared using ANOVA with sex by treatment group as a factor, followed by a comparison between the sexes. Mean rates of changes in carapace length were compared using ANOVA for tortoises that survived for the length of the study with year, sex, and treatment as factors. Rates of mortality for the sex by treatment groups were compared using Pearson's Chi-square and Fisher's Exact tests. Software used for calculations included StatView ${ }^{\mathrm{TM}}$ V.4.51 and 
Table 1 - Summary of Desert Tortoises translocated and their changes in body mass on day of release before and after the opportunity to drink

\begin{tabular}{|c|c|c|c|c|c|c|}
\hline Tortoise \# & Sex & $\begin{array}{c}\text { Experimental } \\
\text { group }\end{array}$ & $\begin{array}{c}\text { Date released } \\
(1997)\end{array}$ & $\begin{array}{l}\% \text { Change in } \\
\text { body mass }\end{array}$ & $\begin{array}{l}\text { Observed } \\
\text { to drink }\end{array}$ & $\begin{array}{c}\text { Excreted urine } \\
\text { or feces }\end{array}$ \\
\hline L1002 & $\mathrm{F}$ & NS & 23 April & 16.67 & Yes & - \\
\hline L1003 & $\mathrm{F}$ & NS & 23 April & 0.00 & No & - \\
\hline L1001 & $\mathrm{J}$ & NS & 23 April & 0.00 & Yes & Feces \\
\hline L1005 & $\mathrm{F}$ & WS & 23 April & 0.00 & No & Feces \\
\hline L1004 & $\mathrm{J}$ & WS & 23 April & 0.00 & Yes & Feces \\
\hline L1006 & M & WS & 23 April & 0.00 & No & Feces \\
\hline L1025 & $\mathrm{F}$ & NS & 29 April & 7.14 & Yes & - \\
\hline L1026 & M & NS & 29 April & 25.00 & Yes & Urine (very little) \\
\hline L1024 & M & WS & 29 April & -3.26 & Yes & Feces \\
\hline L1023 & M & WS & 29 April & 0.00 & No & - \\
\hline L1222 & $\mathrm{F}$ & NS & 05 May & 14.66 & Yes & - \\
\hline L1223 & M & NS & 05 May & 0.00 & No & - \\
\hline L1226 & M & NS & 05 May & 26.56 & Yes & - \\
\hline L1224 & $\mathrm{F}$ & WS & 05 May & -0.06 & No & Feces \\
\hline L1225 & $\mathrm{F}$ & WS & 05 May & -2.13 & No & Feces \\
\hline L1294 & $\mathrm{F}$ & NS & 20 May & 9.46 & Yes & Urine \\
\hline L1296 & M & NS & 20 May & 5.63 & Yes & - \\
\hline L1297 & $\mathrm{M}$ & NS & 20 May & 23.81 & Yes & Urine \\
\hline L1295 & $\mathrm{F}$ & WS & 20 May & 1.89 & Yes & - \\
\hline L1299 & $\mathrm{F}$ & WS & 20 May & -4.74 & No & Urine \\
\hline L1298 & $\mathrm{M}$ & WS & 20 May & 0.00 & - & Feces \\
\hline L1346 & $\mathrm{F}$ & NS & 21 May & 15.00 & Yes & - \\
\hline L1347 & $\mathrm{F}$ & NS & 21 May & 13.81 & Yes & - \\
\hline L1349 & $\mathrm{F}$ & WS & 21 May & 1.19 & No & - \\
\hline L1348 & M & WS & 21 May & 0.00 & No & - \\
\hline L1367 & M & WS & 22 May & 2.27 & Yes & Feces \\
\hline L1368 & M & WS & 22 May & 0.00 & No & - \\
\hline L1363 & $\mathrm{M}$ & WS & 23 May & 1.38 & No & - \\
\hline
\end{tabular}

No datum was recorded as to whether L1298 was seen drinking. Excretion of urine or feces occurred between the measurements of body mass. $\mathrm{F}$ = female, $\mathrm{J}$ = juvenile (undetermined sex), $\mathrm{M}=$ male, $\mathrm{WS}$ = water-supplemented, $\mathrm{NS}$ = not supplemented.

SuperANOVA ${ }^{\mathrm{TM}}$ v.1.11 (Abacus Concepts Inc., Berkeley, CA, USA).

\section{Results}

\subsection{Behavioral observations}

On the days of release, all tortoises exited their initial burrows within $30 \mathrm{~min}$ and ate during the observation period. Tortoises primarily ate dry plants of the following species: Schismus barbatus, Bromus madritensis (rubens), Plantago sp., and Erioneuron pulchellum. Chamaesyce albomarginata and Baileya multiradiata were eaten green. Eight of 13 NS tortoises and 7 of 15 WS tortoises ate cacti (Opuntia basilaris and Opuntia ramosissima).

Half of the tortoises, seven from both the WS and NS groups, were observed digging on the days of release. Most of these animals did not construct complete burrows during the observation period. One male NS tortoise (L1296) successfully completed a burrow in a sandy wash in less than $1.2 \mathrm{~h}$.

Only two tortoises showed obvious signs of stress on their day of release. A NS female (L1222) began frothing at the mouth at 12:45 h on 5 May 1997 and immediately started digging beneath a creosote bush. During the next hour of observation, she stopped frothing, walked to a previous location, began to froth again, and dug beneath another creosote bush where she stopped frothing and remained for the last hour of observation. A WS male (L1298) began frothing at 11:40 h on 20 May 1997, but details of his behavior are unknown. No tortoises showed signs of heat stress during observation periods after the day of release.

\subsection{Body mass}

Adult WS tortoises gained 14.2\% (SD = 7.7) while NS tortoises lost $2.4 \%(\mathrm{SD}=4.4)\left(F_{1,23}=31.7, p=0.0001\right.$; regression coefficient $=-0.012, p=0.0200$ ) of their body masses while in experimental pens before translocation. Natural drinking opportunities during the treatment period were non-existent to extremely limited as no precipitation was recorded at the DTCC in March and May and $1 \mathrm{~mm}$ was recorded in April. After access to water on the days of release, adult NS tortoises increased body mass by $13.2 \%(\mathrm{SD}=9.1)$, while WS tortoises lost $0.25 \%(S D=1.9)\left(F_{1,23}=27.0, p=0.0001\right)$ (Table 1). Many WS tortoises voided feces or urine in the tubs of water. The NS tortoises gained more body mass during the opportunity to drink than they had lost while in the experimental pens (paired t-test: $t_{11}=-4.741, p=0.0006$ ).

Most adult tortoises (24 of 26) lost body mass following their release into the LSTS site until rainfall began in July 


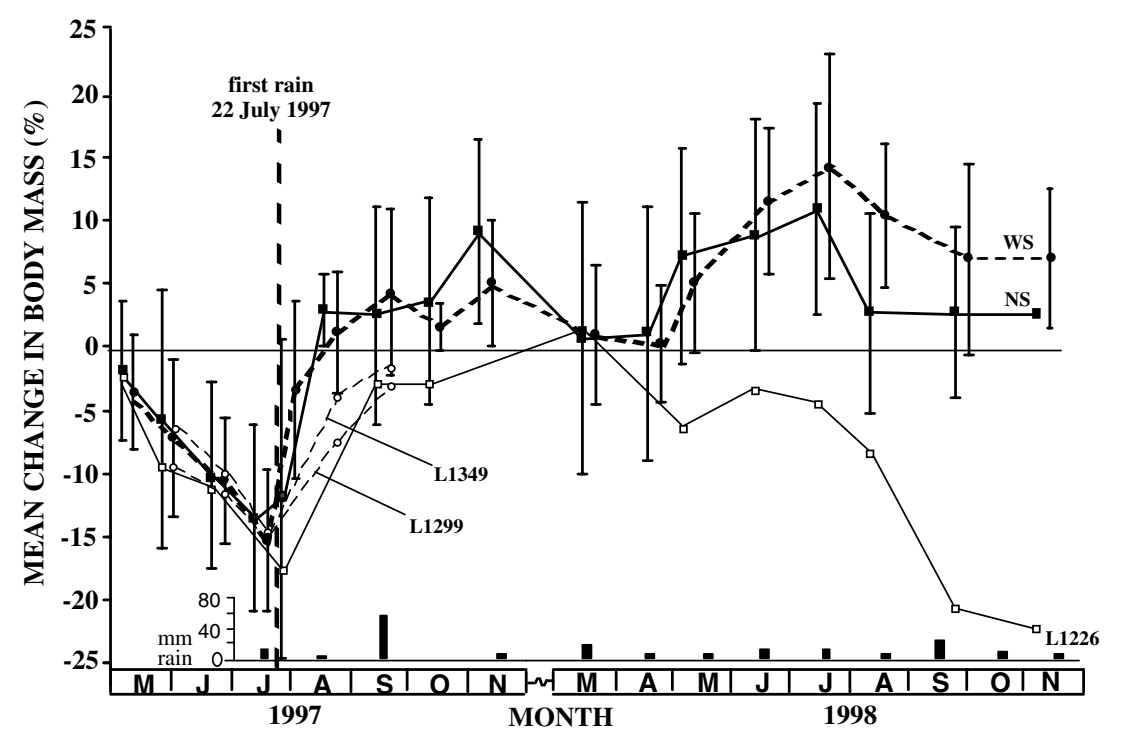

Fig. 1 - Mean change (\%) in body mass ( \pm 1 SD) of WS and NS adult G. agassizii following release at the LSTS site. L1299, L1349, and L1226 were tortoises that showed signs of respiratory disease for $>1$ month and were not included in the group means.

1997. A single tortoise (L1367) voided small amounts of clear urine on three occasions (November and December 1997, January 1998) when handled. Changes in body mass were compared both by date (18 time periods), such that rain events would be reflected in changes in body mass of all tortoises during those time periods, and by number of days since release (four time periods). There were no significant relationships between initial body masses (potential covariate) and changes in body mass when examined by day since release or by date. Three tortoises (L1226, L1299, L1349) had visible signs of respiratory disease for extended periods of time and their changes in body mass were not included in the comparisons. Changes in body mass did not differ across repeated measures by date for the sexes $\left(F_{1,18}=0.229\right.$, $p=0.6378)$, treatments $\left(F_{1,18}=0.123, p=0.7300\right)$, or the sex by treatment interaction $\left(F_{1,18}=0.552, p=0.4670\right)$. In addition, WS and NS tortoises did not differ within time periods examined $\left(F_{16,142}=1.009, p=0.4507\right)$ (Fig. 1). When controlling for number of days since release, groups of males and females with and without supplemental water (sex by treatment interaction) did not have different changes in body mass across all days $\left(F_{1,18}=0.379, p=0.5458\right)$ or within the time periods $\left(F_{3}\right.$, ${ }_{39}=0.510, p=0.6777$ ) (Fig. 2). Throughout 1998, groups that had been with or without supplemental water were heavier on average than they were on the days that they were released (Figs. 1 and 2).

\subsection{Carapace length}

Tortoises that survived the length of the study grew much more slowly in $1997(0.001 \mathrm{~mm} /$ day, SD =0.009) than they did in $1998(0.026 \mathrm{~mm} /$ day, $\mathrm{SD}=0.022) \quad\left(F_{1,26}=12.696\right.$, $p=0.0014)$. No significant effects were produced by sex $\left(F_{1,26}=2.834, p=0.1043\right)$, treatment $\left(F_{1,26}=0.437, p=0.5143\right)$, or any of the interactions. When data from 1997 and 1998 were pooled and a single rate of change in carapace length for each tortoise was calculated for the length of the study, adult WS tortoises grew significantly faster overall $(0.014 \mathrm{~mm} /$ day, $\mathrm{SD}=0.006)$, than did NS tortoises $(0.007 \mathrm{~mm}$ / day, $\mathrm{SD}=0.006)\left(F_{1,15}=6.230, p=0.0247\right)$. The data on five tortoises ended in September 1997, so we examined changes in carapace length for all tortoises through the end of August 1997. Interestingly, the tortoises shrank during this period by an average of $0.0145 \mathrm{~mm} /$ day $(\mathrm{SD}=0.0195)$. Only the two juveniles and two of the adults had positive growth rates during this time.

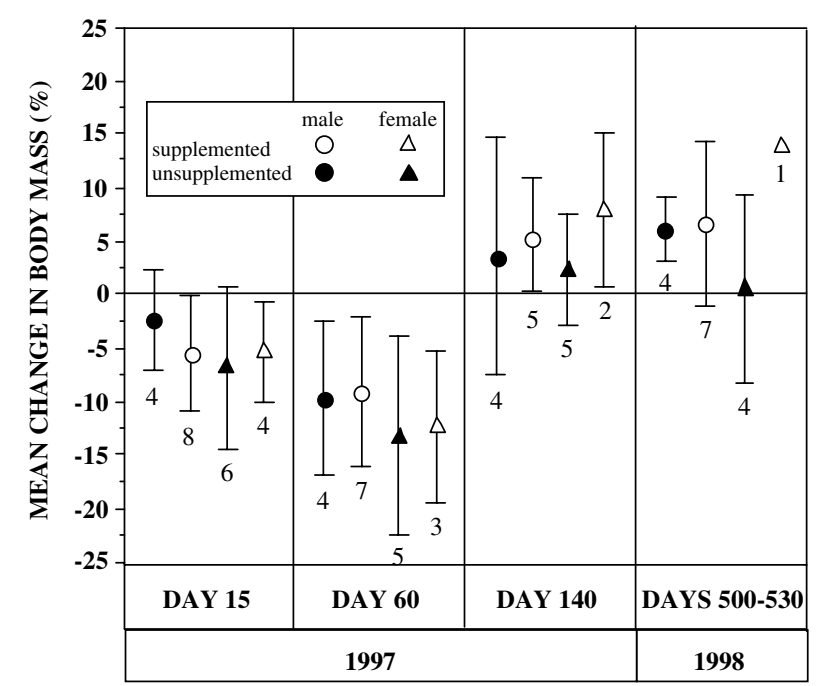

Fig. 2 - Mean change (\%) in body mass ( $\pm 1 \mathrm{SD}$ ) of adult G. agassizii from day of release. Sample sizes are given below each mean. Day 15 occurred from 7 May to 6 June, day 60 from 21 June to 20 July, day 140 from 9 September to 8 October, and days 500-530 from 29 September to 5 October. In 1998 measurements were recorded monthly, rather than for specific days since release. 


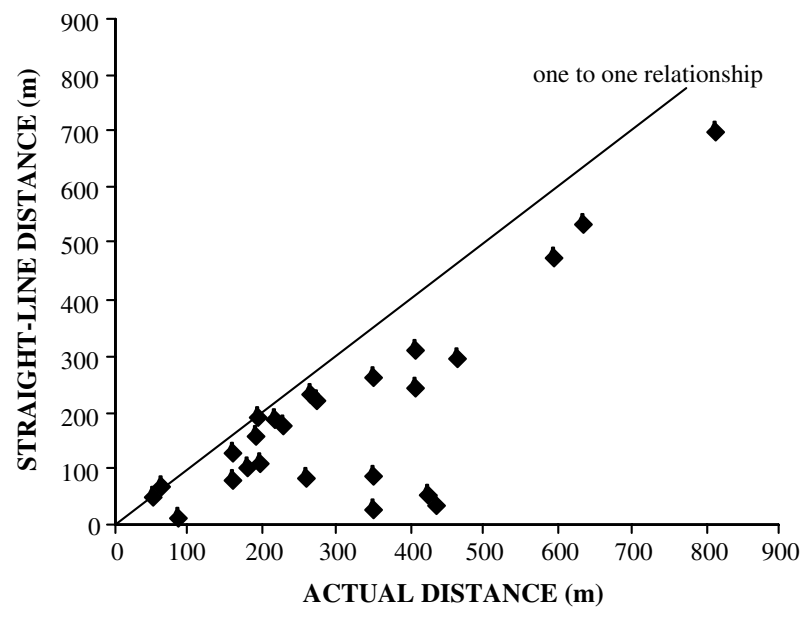

Fig. 3 - Straight-line and actual distances moved from initial burrow on day of release. The line represents a one to one relationship between the two metrics of distance moved. Tortoises with points close to the line traveled in nearly straight lines from their initial burrows. See text for discussion of tortoises that deviated from the line.

\subsection{Movement}

All but two tortoises moved away from their burrows on the days of their release. Movement patterns varied from nearly straight-line travel for many of the animals to meandering travel within the area of release (Fig. 3). There were no differences in actual or straight-line distances moved from initial burrows on days of release for the sexes (actual: $F_{1,19}=$ 0.010, $p=0.9225$; straight-line: $F_{1,19}=0.206, p=0.6551$ ), the treatments (actual: $F_{1,19}=1.483, p=0.2382$; straight-line: $F_{1,19}=0.621, p=0.4403$ ) or the sex by treatment interaction (actual: $F_{1,19}=0.455, p=0.5079 ;$ straight-line $F_{1,19}=0.326$, $p=0.5750$ ). The amounts of time that the tortoises were observed moving were used as covariates (actual: regression coefficient $=0.773, p=0.0649$; straight-line: regression coefficient $=0.392, p=0.5917$ ).

The straight-line distances moved in 1997 by the groups were compared for six time periods. WS females were not included in the analysis because only one tortoise was not lost to mortality or transmitter failure at some point during the six time periods examined. The sex by treatment groups did differ $\left(F_{2,12}=5.86, p=0.0168\right)$. Male WS tortoises moved significantly farther from the area of release than did NS males (Scheffe's S $p=0.0172$ ) (Fig. 4a). Most of the movement away from the points of release occurred during the first 2 weeks following release. The tortoises did not show tendencies to orient northward toward the DTCC and the Las Vegas Valley (Fig. 5).

Total distances moved in 1997 also were compared by adding together the straight-line segments among locations (for the same periods of time that distance from point of release was calculated). Again WS females were not included in the overall analysis and the sex by treatment groups were different $\left(F_{2,12}=4.48, p=0.0352\right)$ with WS males moving farther in total distance than NS males (Scheffe's S $p=0.0383$ ). Approx- imately 20 weeks after release (one of the six time periods examined), total distance moved averaged $5845 \mathrm{~m}$ ( $S D=2633)$ for WS males, $1872 \mathrm{~m}(\mathrm{SD}=1738)$ for WS females, 1781 (SD = 784) for NS males, and $3182 \mathrm{~m}$ (SD = 1950) for NS females. Total distances moved for animals with data points in the last period examined were not correlated with the number of relocation events $\left(R^{2}=0.052, F_{1,13}=0.719, p=0.4118\right)$.

In their second season after release, tortoises remained much closer to their hibernacula than they had to their release burrows. The mean distance from hibernacula to areas of activity from May through September 1998 (11 time periods examined) was $275 \mathrm{~m}(95 \% \mathrm{CI} \pm 29.18)$ for all tortoises with no differences among the sex by treatment groups $\left(F_{2,11}=0.370, p=0.6991\right)$ (Fig. $\left.4 b\right)$. Two WS males (L1298 and L1363) had movement patterns unlike those of the other tortoises (Fig. 4b). Their outlying points, as well as data from the single WS female were not included in the comparison.

Total distances moved in 1998 also were compared. Tortoises were located 21-38 times after emergence from hibernacula in 1998. The total distances moved and the number of relocation events between emergence from hibernacula and return to hibernacula were not correlated $\left(R^{2}=0.0004, \quad F_{1,16}=0.007\right.$, $p=0.9346)$. Total distances moved did not differ for the sex by treatment groups $\left(F_{2,13}=2.264, p=0.1433\right)$. Adult tortoises moved $5160 \mathrm{~m}(\mathrm{SD}=1633)$ in total distance during 1998.

\subsubsection{Use of burrows}

Tortoises used burrows as shelter sites during the study with no differences in the number of burrows used among the sex and treatment groups (sex: $F_{1,14}=0.012, p=0.9161$; treatment: $F_{1,14}=0.933, p=0.3506$; interaction: $F_{1,14}=0.012, p=0.9161$ ). Individuals tracked continuously through the end of 1997 used an average of six burrows (SD =1.9, range $=3-10)$, and tortoises used eight burrows ( $\mathrm{SD}=2.6$, range = 5-13) in 1998 . On average, tortoises continued to use only one $(\mathrm{SD}=0.87$, range 0-3) burrow in 1998 that they first used in 1997.

Two tortoises returned to their initial human-made burrows. A WS female (L1295) was found in her initial burrow on the morning of 21 May 1997, 1 day after her release. The previous day this tortoise moved $439 \mathrm{~m}$ during the $3.5 \mathrm{~h}$ observation period (129 m straight-line distance). On 8 June 1998, a NS male (L1297) was found in the burrow within which it had been released on 20 May 1997. This tortoise was found up to $291 \mathrm{~m}$ from this burrow for all prior locations.

Many tortoises used their 1997-1998 hibernacula as shelter sites in 1998. Eleven of the 18 tortoises for which hibernacula were known returned to hibernacula after emergence. Two tortoises used the same burrows as both their 1997-1998 and 1998-1999 hibernacula.

\subsubsection{Home range}

Home ranges were calculated for adults in 1998 (Fig. 6), except for the two males (L1298 and L1363) that moved long distances in September 1998. Home range sizes did not differ for the sex by treatment groups $\left(F_{2,11}=3.433, p=0.0694\right.$; single WS female not included) and males were not affected by treatment $\left(F_{1,8}=1.225, p=0.3006\right)$. Because males and females typically have different home range sizes, data from treatment groups were combined and sexes were compared. The mean size of home ranges for male tortoises, 25.5 ha 

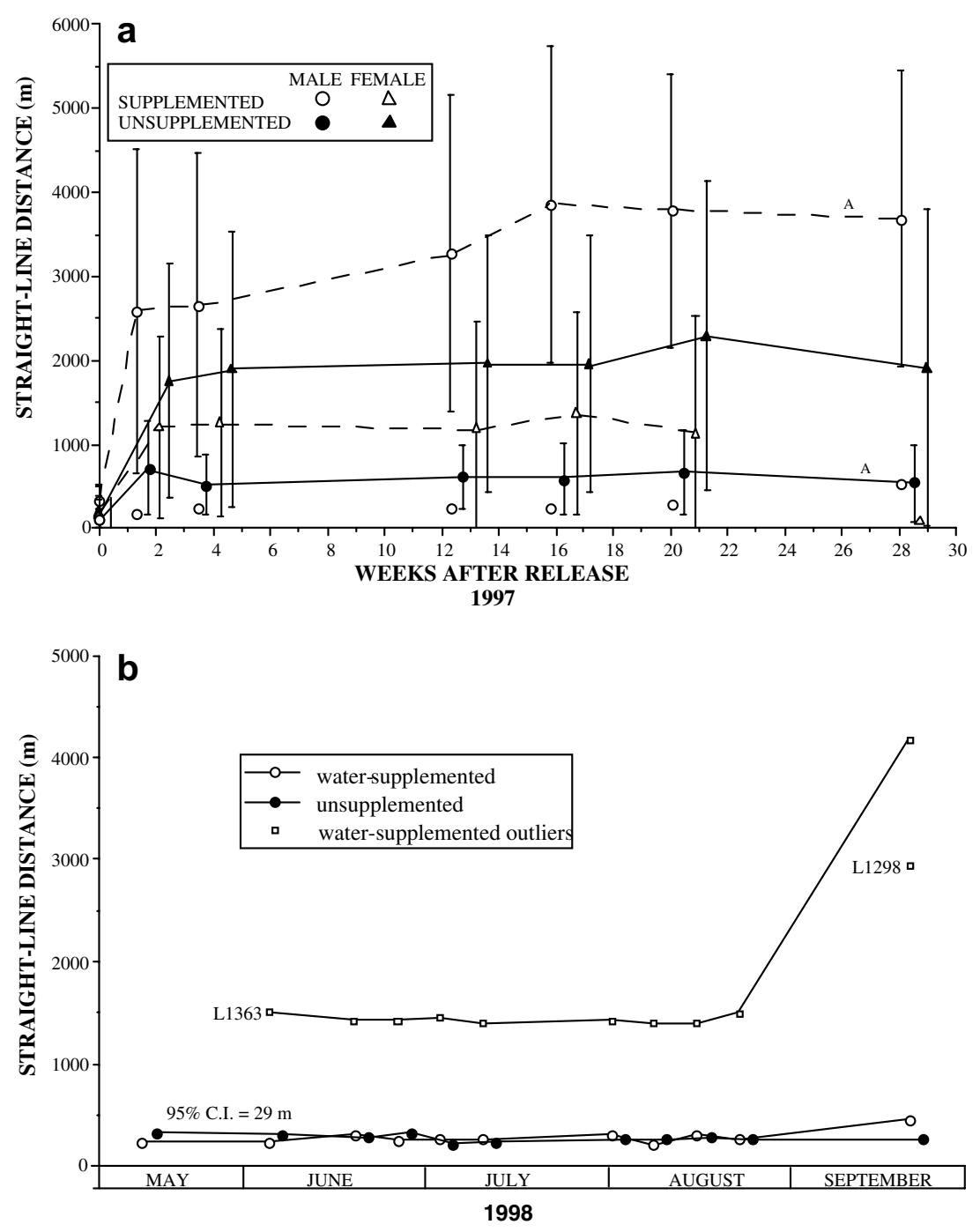

Fig. 4 - (a) Mean straight-line distances of G. agassizii from their initial burrows in 1997. Error bars represent one standard deviation. WS males moved significantly farther than did NS males (A). The open circles without connecting lines represent an outlier of the WS males (L1023). The open triangle without a connecting line represents a single WS female (L1005). (b) Mean straight-line distances from hibernacula of WS and NS adult G. agassizii in 1998. Two tortoises (L1363, L1298) had points that were outliers of the WS tortoises. WS and NS tortoises did not differ across all time periods $F_{1,15}=0.053$, $p=0.8209$, or within time periods $F_{10,139}=1.310, p=0.2309$.

$(\mathrm{SD}=15.1$, range $=9.94-62.73)$, was larger than that of females, 8.9 ha $(S D=1.9, \quad$ range $=6.89-11.14) \quad\left(F_{1,13}=5.804\right.$, $p=0.0315)$. Tortoises located more times did not have larger home range sizes than those located fewer times (regression coefficient $=-0.016, p=0.1914)$.

\subsection{Mortality}

All six tortoise deaths occurred in 1997 (Appendix) giving a mortality rate of $21.4 \%$ ( $10.7 \%$ unknown outcome, $67.9 \%$ known survival) for tortoises from release to hibernation in 1997. Mortality rates were not significantly different for the main effects of sex (chi square $=3.467, \mathrm{df}=1$, Fisher's Exact $p=0.1602$ ), water treatment (chi square $=0.5159, \mathrm{df}=1$, Fisher's Exact $p=0.6546$ ), or among the sex by treatment groups (chi square $=4.573, \mathrm{df}=3$, chi squared $p=0.2059$ ).
The only adult male that died (L1348) had been supplemented with water. This animal had traveled as far as $1241 \mathrm{~m}$ from its initial burrow during the 48 days that it lived at the LSTS site. The tortoise had wet nares, a possible sign of disease, 1 week before its death. On 7 July 1997, the tortoise's intact carcass was found $1185 \mathrm{~m}$ from its initial burrow, and it had used four other burrows. There was no evidence that predation was the cause of death.

Two NS females died. L1002 was never found using a burrow between its release and death. This tortoise traveled long distances following release, and 21 days after release (13 May) its intact carcass was found overturned $4195 \mathrm{~m}$ from the initial burrow. L1025's carcass was found 166 days after release (11 October). The carcass was found soon after death at a location $5399 \mathrm{~m}$ from its initial burrow. The condition of the carcass and manner in which it was slightly buried and 


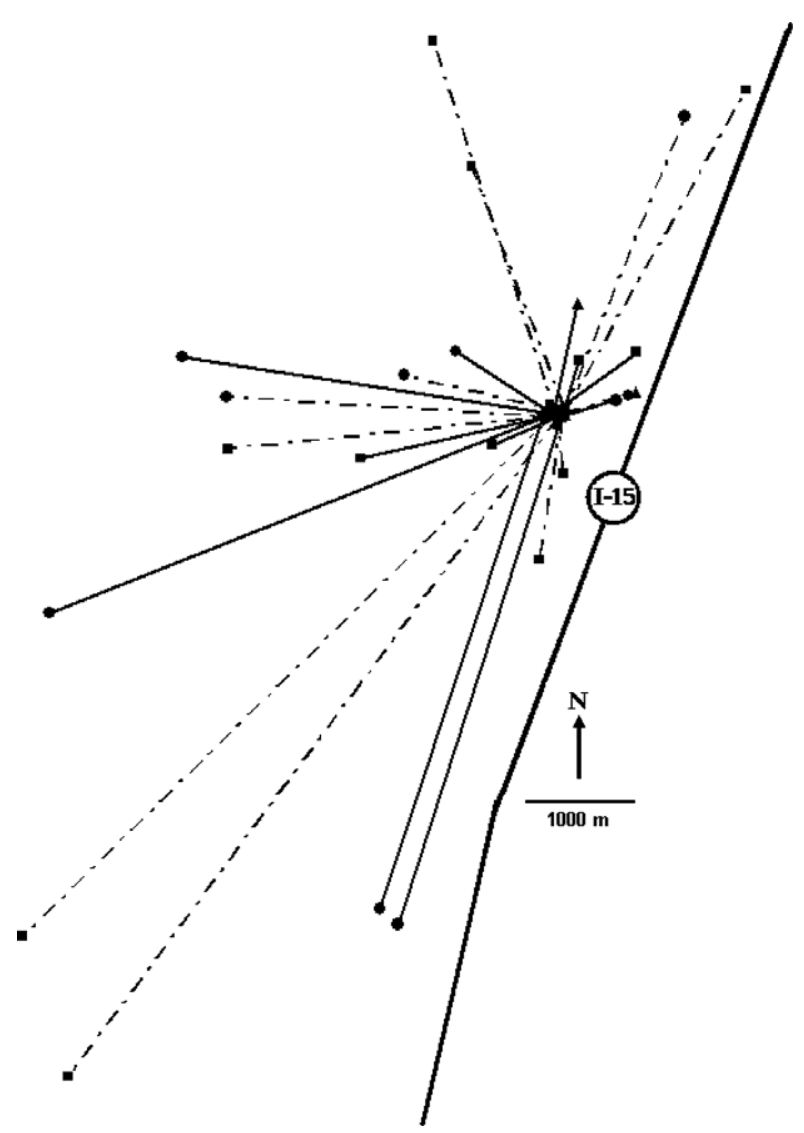

Fig. 5 - Straight lines from initial burrows to last known locations of all tortoises in 1997. Solid lines are NS, broken lines are WS, circles are females, squares are males, and triangles are juveniles.

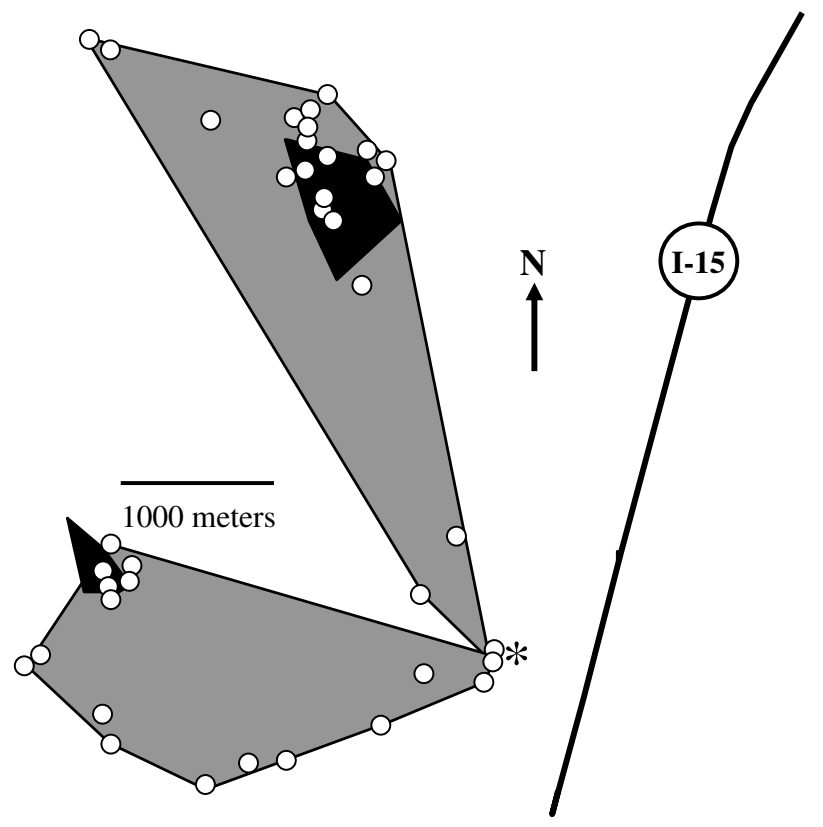

Fig. 6 - Movements by WS male L1006 (upper) and NS female L1222 (lower). 1997 locations (white dots) and minimum convex polygon home ranges for 1997 (grey) and 1998 (black) to show inappropriateness of calculating home ranges for first-season translocatees. $*$ marks the release area. Interstate Highway 15 runs along the eastern border. covered with grasses was consistent with predation by either bobcat (Lynx rufus) or mountain lion (Felis concolor).

Three WS females died. Females L1299 and L1225 were found with wet nares before their deaths and were preyed upon or scavenged. L1299's radio signal was last heard 117 days after release (13 September) and its carcass was located 18 February 1998. L1225 only used a single burrow up to its death 57 days after release (30 June). L1295 was found using one burrow until 91 days after release (18 August) when it was found dead in its second burrow. The burrow was located in a small wash and had collapsed, encasing the carcass in soil and cobble. The circumstances suggest that this tortoise remained in the burrow during a rainstorm and did not dig itself out when the burrow collapsed.

\section{Discussion}

\subsection{Behavioral observations}

Although the tortoises had spent years in captivity at the DTCC, upon release they were capable of finding appropriate food items, digging burrows, and generally using resources as necessary for survival in the wild. A previous translocation study raised concerns that released captives may have diminished ability to forage, find shelter sites, respond appropriately to environmental conditions, and avoid predators because all 5 tortoises died after translocation (Berry, 1974).

Overheating was shown to be a problem for tortoises in another translocation study with 6 of 7 deaths attributed to lethal body temperatures, three of which occurred on days of release (13 June and 2 July 1977) and three within 2 weeks of release (Cook et al., 1978; Cook, 1983). Tortoises that approach lethal body temperatures often produce large amounts of foaming saliva, which spread to the head and neck (McGinnis and Voigt, 1971). Two of our tortoises (L1222, L1298) were moving around the area of release and frothing at the mouth while all other tortoises released on those days were in shaded locations either at rest or digging beneath shrubs. During the observation periods both tortoises rested briefly in shade although they did not use shade competently as temperatures increased during the day. Both tortoises survived the length of the study, indicating that inappropriate thermoregulatory behaviors were likely limited a short period of time immediately following translocation. Problems associated with overheating would likely be minimized by conducting translocations in early to mid-spring, rather than late spring to summer, and by releasing tortoises such that on their first day they have several hours to move about when ambient temperatures are not likely to be problematic.

\subsection{Body mass}

Fluctuations in body mass of the Desert Tortoise largely are caused by changes in state of hydration (Minnich, 1977; Peterson, 1996a). When water is available, Desert Tortoises commonly drink 11-28\% of their body mass (Minnich, 1977; Nagy and Medica, 1986), and in some cases, Desert Tortoises have been observed to increase body mass up to $43 \%$ after drinking (Miller, 1932). 
Our concern that daily water supplementation in captivity could cause negligence in bladder water retention after release and our prediction that WS tortoises would lose more body mass after release than would NS tortoises were not supported by our data. Indeed, all tortoises lost similar amounts of body mass after release during the dry period preceding the first rain (22 July 1997). As expected, all tortoises gained body mass when rain provided drinking water. The two groups of tortoises continued to have similar fluctuations in body mass for the duration of the study.

Evaporative water loss is low in Desert Tortoises, but highly active animals lose more water through evaporation than do less active animals (Tracy, 1992). Desert Tortoises in California, at Ivanpah Valley (IV) and the Desert Tortoise Natural Area (DTNA), had a mean net water loss rate of $<2 \mathrm{~mL} \mathrm{~kg}^{-1}$ day $^{-1}\left(0.083 \mathrm{mg} \mathrm{g}^{-1} \mathrm{~h}^{-1}\right)$ during a severe drought; the typical rate was $1 \mathrm{~mL} \mathrm{~kg}^{-1} \mathrm{day}^{-1}\left(0.042 \mathrm{mg} \mathrm{g}^{-1} \mathrm{~h}^{-1}\right)$ (Peterson, 1996a). Based on Peterson's observed rates, the tortoises at the LSTS site are predicted to lose $1.5-3.0 \%$ of their starting body masses after 15 days, but the actual body mass lost by LSTS tortoises was $5.3 \%$. The LSTS tortoises are predicted (from Peterson's data) to drop 6.0-12.0\% of their starting body masses after 60 days. The $10.8 \%(S D=5.7)$ lost by LSTS tortoises is within the predicted range.

\subsection{Carapace length}

The fifth wettest year on record for southern Nevada (as measured in the Las Vegas Valley, approximately $45 \mathrm{~km}$ northwest of the LSTS site) occurred in 1998, with wettest ever February $(73 \mathrm{~mm})$ and tenth wettest March $(26 \mathrm{~mm})$ (Gorelow, 2005). February and March 1997 had below normal rainfall with $5 \mathrm{~mm}$ and $0 \mathrm{~mm}$ respectively. Late winter and early spring rains allow for germination and growth of the annual plants that make up much of the tortoise's diet (Oftedal, 2002). Tortoises translocated to the LSTS site grew about 25 times faster in carapace length during 1998 than they did during 1997. Shell growth positively correlates with rainfall (Medica et al., 1975; Nagy and Medica, 1986) and likely is dependent on nitrogen provided by green plants (Peterson, 1996b). Additionally, with drinking water available, tortoises can increase consumption of forage without elevating plasma solute concentrations to dangerous levels. The observed shrinking of carapace length from the time of release until the end of August 1997 helps to account for the large difference in growth rates for 1997 and 1998. During a tortoise's lifetime there are likely many periods when no growth or shrinking occurs. Adults and juveniles may experience no growth or shrinking during drought, yet in productive seasons juveniles may rapidly approach the size of more slowly growing older tortoises. Decrease in carapace length during drought was noted for two juvenile tortoises in another study (Berry et al., 2002) and shrinking has been measured in marine iguanas in times without food (Wikelski and Thom, 2000).

Carapace growth was marginally greater for tortoises that were supplemented with water although the small difference in growth rate was only detectable when the data from 1997 and 1998 were combined. The increase in size was not great enough to expect increased reproductive capabilities or decreased vulnerability to certain predators.

\subsection{Movement}

Familiarity with surroundings likely influenced the reduced movements made by tortoises in 1998 compared to those in 1997. We translocated a cohort of tortoises to the LSTS site in spring 1998 as part of another experiment. These tortoises moved an average of $1579 \mathrm{~m}(\mathrm{SD}=1071)$ from their initial burrows that year whereas tortoises released the year before moved only $275 \mathrm{~m}$ from their 1998 start points (hibernacula). The two cohorts were very similar vis-à-vis their movements in their first year after release suggesting that reduction of movement by tortoises in their second year was not simply caused by break of the drought, but by familiarity with the area.

The concept of home range was described and defined by Burt (1943) as "that area traversed by the individual in its normal activities of food gathering, mating, and caring for young." Occasional movements to points outside of the area typically used should not be included in the home range and home ranges should not be calculated for animals that are wandering (Burt, 1943). The movement patterns of tortoises during their first season at the translocation site clearly were not consistent with the definition. Calculations of home ranges appeared to be appropriate for most animals in their second season after release. Desert Tortoises do make lengthy journeys outside of their normal activity areas to exploit resources such as calcium rich soils (Marlow and Tollestrup, 1982). Three tortoises that made long distance movements in 1998 did not return to their previous areas of activity, so home range calculations were inappropriate. Home range sizes of female (8.9 ha, range 6.9-11.1) and male (25.5 ha, range 9.9-62.7 ha) tortoises during their second activity season at the LSTS site were comparable to the home range sizes of native wild Desert Tortoises in a nearby valley in a nondrought year (females 5.9-11.2 ha, males 7.7-49.0 ha) (O'Connor et al., 1994). The characteristic home range sizes and the short distances moved from hibernacula provide evidence that second-year translocatees were similar to native wild tortoises from other studies.

Fidelity to the release site shown by some tortoises during their first and second seasons after release could, in part, be predicted by examining the patterns of movement on days of release. Six tortoises deviated greatly from straightline travel and/or moved small straight-line distances from their initial burrows (Fig. 3). Two of these animals were frothing from the mouth. These two tortoises may have meandered because they became overheated, or the meandering may have been due to unfamiliarity with the surrounding area and misuse of shade resources. The other four tortoises (L1295, L1297, L1346, and L1005) were closer to their initial burrows $(\leqslant 110 \mathrm{~m})$ at their last known locations in 1997 than were the other tortoises. The four tortoises represented each of the sex by treatment groups except for the WS males, who were already making long, linear movements away from their initial burrows. Three of the four tortoises survived through 1998 and were closest to their initial burrows at their last locations in 1998 as well $(139-415 \mathrm{~m})$ (Table 2). All other tortoises moved greater straight-line distances from their initial burrows of release and/or tended to move in nearly straight-lines from their 
Table 2 - Straight-line distances moved by tortoises

\begin{tabular}{|c|c|c|c|c|c|}
\hline Tortoise \# & Sex & Experimental group & 1997 Straight-line (m) & 1998 Straight-line (m) & Final straight-line $(\mathrm{m})$ \\
\hline L1002 & $\mathrm{F}$ & NS & $4195(21)^{*}$ & - & - \\
\hline L1003 & $\mathrm{F}$ & NS & 4314 (239) & 65 & 4262 \\
\hline L1025 & $\mathrm{F}$ & NS & $3483(139)^{*}$ & - & - \\
\hline L1222 & $\mathrm{F}$ & NS & 2433 (227) & 290 & 2706 \\
\hline L1294 & $\mathrm{F}$ & NS & $349(2)^{*}$ & - & - \\
\hline L1346 & $\mathrm{F}$ & NS & $67(210)$ & 349 & 415 \\
\hline L1347 & $\mathrm{F}$ & NS & $836(211)$ & 174 & 833 \\
\hline L1001 & $\mathrm{J}$ & NS & $886(120)^{*}$ & - & 2322 \\
\hline L1026 & $\mathrm{M}$ & NS & $1332(233)$ & 158 & 1491 \\
\hline L1223 & M & NS & 467 (195) & 343 & 721 \\
\hline L1226 & M & NS & $685(226)$ & 943 & 596 \\
\hline L1296 & M & NS & $404(211)$ & 260 & 660 \\
\hline L1297 & M & NS & $110(211)$ & 244 & 220 \\
\hline L1005 & $\mathrm{F}$ & WS & $23(238)$ & 144 & 139 \\
\hline L1224 & $\mathrm{F}$ & WS & $2103(132)^{*}$ & - & - \\
\hline L1225 & $\mathrm{F}$ & WS & $1049(57)^{*}$ & - & - \\
\hline L1295 & $\mathrm{F}$ & WS & $92(91)^{*}$ & - & - \\
\hline L1299 & $\mathrm{F}$ & WS & $2591(117)^{*}$ & - & - \\
\hline L1349 & $\mathrm{F}$ & WS & $422(117)^{*}$ & - & - \\
\hline L1004 & $\mathrm{J}$ & WS & 483 (239) & 60 & 477 \\
\hline L1006 & $\mathrm{M}$ & WS & 3206 (238) & 95 & 3399 \\
\hline L1023 & M & WS & $527(232)$ & 0 & 527 \\
\hline L1024 & M & WS & $2118(233)$ & 0 & 2118 \\
\hline L1298 & M & WS & $2893(211)$ & 2910 & 5802 \\
\hline L1348 & $\mathrm{M}$ & WS & $1185(48)^{*}$ & - & - \\
\hline L1363 & $\mathrm{M}$ & WS & 5429 (208) & 3777 & 6126 \\
\hline L1367 & $\mathrm{M}$ & WS & $6245(210)$ & 771 & 6975 \\
\hline L1368 & $\mathrm{M}$ & WS & 2080 (209) & 789 & 1725 \\
\hline
\end{tabular}

burrows of release. These tortoises ended up 404-6245 m from their initial burrows in 1997. Some tortoises traveled long distances away from the release area in nearly straight-lines and others started traveling in straight-lines, but switched directions after the observation periods on days of release and remained near to the release area. The tendency for some tortoises to travel in straight-lines for long distances after translocation has been described previously (Berry, 1974). In that study, only translocatees that were originally captured in the wild tended to travel far and/or in straight-lines from points of release. Translocatees that were former captives stayed within a few hundred meters of their points of release and did not venture more than $100 \mathrm{~m}$ from burrows that they established (Berry, 1974). A recent study of the Gopher Tortoise (Gopherus polyphemus), which inhabits the southeastern United States, suggests that fidelity to the release area increases with increased time spent in temporary outdoor enclosures at the site (Tuberville et al., 2005). While there is currently more contiguous habitat remaining for Desert Tortoises than for Gopher Tortoises, there could be situations where reducing movements away from the release area would be desirable and achievable through various methods. Although eliminating water supplementation prior to release did reduce the dispersal of males in our study, it did not appear to affect females similarly.
Homing attempts, especially for short distance translocations, have been shown to be problematic for various species including the Gila Monster (Heloderma suspectum), which shares its distribution with the Desert Tortoise (Sullivan et al., 2004). In one study, translocated Desert Tortoises of captive origin showed little to no tendency to orient toward home, while 9 of 12 tortoises of wild origin did orient toward home (Berry, 1974). Eastern Box Turtles (Terrapene c. carolina) moved 32-131 km did show a weak, yet variable tendency to home (Cook, 2004). The tortoises in our study did not tend to travel toward home, possibly due to the distance between the LSTS site and their former homes.

\subsection{Mortality}

One might expect that traveling long distances in unfamiliar surroundings would increase translocated tortoises' chances of mortality. Desert Tortoises have good spatial memories and will reuse shelter sites and other resources in locations that are familiar to them (Berry, 1974; Marlow and Tollestrup, 1982). Although the WS males traveled long distances from the release area before reducing their movements, only one WS male died.

The mortality rates of females and males were not significantly different for the LSTS tortoises, however, given the small sample sizes and extremely low male mortality as 
Table 3 - Numbers of translocated tortoises lost at the LSTS site

\begin{tabular}{cccccc} 
Sex & Experimental group & Total released & Partial carcasses & Intact carcasses & Lost radio signals, no carcass \\
\hline F & NS & 7 & 1 & 1 & 1 \\
F & WS & 6 & 2 & 1 & 2 \\
M & NS & 5 & 0 & 0 & 0 \\
M & WS & 8 & 0 & 1 & 0 \\
J & NS & 1 & 0 & 0 & 0 \\
J & WS & 1 & 0 & 0 & 0 \\
\hline
\end{tabular}

Partial carcasses had evidence of predation or scavenging. $\mathrm{F}=$ female, $\mathrm{M}=$ male, $\mathrm{J}=$ juvenile (undetermined sex), NS = not supplemented prior to release, WS = water-supplemented prior to release.

compared to females, this question should be addressed with a larger sample size. In a previous study in which translocated and resident tortoises were monitored in plots of irrigated and unirrigated desert habitat, female translocated tortoises were reported to have a higher mortality rate than resident females, resident males, or translocated males (SAIC, 1993). We recalculated mortality rates for tortoises in unirrigated plots from the first two seasons after release by requiring recovery of a carcass for a tortoise to be considered dead. This new analysis of the data indicates that the translocated females had a mortality rate of $20.0 \%$ in two activity seasons, while resident females, resident males, and translocated males experienced no mortality (SAIC, 1993).

In times such as drought when predators (e.g. coyotes, kit foxes, bobcats) have fewer mammalian prey available, they will increase take of less preferred prey including tortoises (Woodbury and Hardy, 1948; Berry, 1974). During droughts, coyotes apparently killed most of the tortoises in one study at the DTNA (Peterson, 1994) and 21-28\% of the marked wild population in a study near Ridgecrest, California were killed by canids. Predation was the suspected cause of death of most wild resident and first-season translocated tortoises in a study concurrent with ours that took place approximately $30 \mathrm{~km}$ to the north at Bird Spring Valley (BSV), Nevada (Nussear, 2004). Although half of the carcasses in our study showed signs of having been eaten, it should not be assumed that predation was the cause of death in all cases (Table 3). It is possible that the tortoises died of other causes and were quickly scavenged, or tortoises may have become dehabilitated and therefore susceptible to predation. Many times the cause of death of released animals is reported to be predation without dehabilitation considered as the ultimate cause (Soderquist, 1994). Two of the three animals whose carcasses were eaten had damp nares, a possible sign of disease, before death.

Wild tortoises were not equipped with telemetry radios at the LSTS site, so a proper experimental control with which to compare the mortality rate of translocatees did not exist. Tortoises translocated to BSV in the spring of 1997 had a total mortality rate of $11.7 \%$ (7 of 60 released) that year, while residents at BSV had a mortality rate of $15.1 \%$ (8 of 53) that same year (Nussear, 2004). The mortality rates of translocated and resident animals at BSV were not significantly different (chi square $=2.563 \mathrm{E}-4, \mathrm{df}=1$, Fisher's Exact $p>0.9999$ ). The mortality rate of $21.4 \%$ ( 6 of 28 released) at the LSTS site was not different from the $11.7 \%$ calculated for tortoises translocated to BSV (chi square $=1.445, \mathrm{df}=1$, Fisher's Exact $p=0.3327$ ). The data from BSV and previous studies suggest that all tortoises at the LSTS site, regardless of translocated or resident status, likely were negatively impacted by drought conditions at the site in 1997. Additionally, a cohort of tortoises that we released at the LSTS site for another experiment in the spring of 1998 had a 2.5\% (1 of 40) mortality rate that year, further suggesting that the translocation itself did not strongly influence mortality rates, while drought did.

\subsection{Conservation implications}

The translocation of tortoises to the LSTS site in spring of 1997 occurred at the end of a period with little rainfall. Annual vegetation was sparse and dry, and there was no rainwater for tortoises to drink until late July 1997. Because the conditions at the LSTS site were harsh, the ability of tortoises to adjust to life in the wild could be examined under adverse conditions. Despite harsh conditions, most of our translocated tortoises quickly became adept at life in the wild. Although initial mortality rates may be lower when translocations occur in years with plentiful rainfall, translocations during dry years may be acceptable because drought conditions likely affect mortality of resident and translocated tortoises similarly. It may be beneficial, however, to release tortoises with unknown histories (e.g. unknown access to sufficient food and water in years prior to translocation) in non-drought years. At small translocation sites or when goals include increased density in particular portions of the site, travel by male tortoises may be reduced by not providing supplemental water from the end of last captive hibernation up to release in spring. We conclude that, regardless of water supplementation regimen, initial success in our translocation demonstrates high potential for longerterm successes. We strongly suggest that translocation be considered a valid tool available for conservation of the Desert Tortoise. Although translocated tortoises fared well during their initial adjustment period, long-term survival and productivity of these animals will be subject to the same factors that continue to dwindle populations of the Desert Tortoise across its range. If we are able to effectively abate the myriad of threats that lessen the likelihood of this species' persistence, translocation of tortoises to appropriate areas will be essential to bolster decimated populations toward a sustainable existence. 


\section{Acknowledgements}

We thank the US Fish and Wildlife Service; Clark County, Nevada through their Multiple Species Habitat Conservation Plan; and the Biological Resources Research Center at the University of Nevada-Reno for funding our project. Our project site was managed by the Bureau of Land Management, and we thank S. Slone for helping to make this site available. Thanks to J. Bresson, R. Bubb, C. Bulloch, J. Bulloch, M. Damon, N. Dewar, J. Duncan, S. Frantzeskos, R. Goldman, A. Hanlon, A. Hawkins, C. Holmes, K. Johnston, D. Jones, K. Kettenring, A. Knoshaug, A. Mahar, K. Paxson, J. Ranson, P. Sharky, B. Shepard, J. Sikich, M. Taggart, M. Thomas, and E. Vining who assisted in the project as Student Conservation Association Volunteers. B. Tomica, K. Murphy, R. Loubeau, and H. Leach of the US Geological Survey's Biological Resources Division contributed to field work. C. LaBar, M. Berkowitz, and the crew of Southern Nevada Environmental Inc. helped with experimental setup at the Desert Tortoise Conservation Center. S. Jenkins, W. Sweigert and W. Wallace had suggestions on statistical analyses. R. Espinoza, T. Esque, C. Fowler, J. Hayes, K. Nussear, M. Saethre, E. Simandle, and D. Wilson provided comments on drafts of the master's thesis upon which this manuscript is based. We thank Julie Yee and three anonymous reviewers for comments that improved this manuscript. Experiments were conducted according to IACUC guidelines (University of Nevada IACUC Protocols A95/96-19, A98/99-19, A98/99-29, and A95/96-28) and under permits issued by the US Fish and Wildlife Service (PRT-801045 and PRT-702631 with subpermits NBSNER3 and BRDNER-4) and Nevada Division of Wildlife (S-14528 and S-17841).

\section{Appendix}

Release histories of $28 \mathrm{G}$. agassizii at the LSTS site. Release dates are indicated by open shapes for the WS tortoises and by filled shapes for the NS tortoises, with circles for females, squares for males, and triangles for juveniles (unknown sex). $\mathrm{L}=$ lost radio signal; $\mathrm{C}=$ carcass found; $\mathrm{F}=$ live tortoise found; \# = known transmitter failure. Solid lines indicate that a tortoise was monitored continuously and dashed lines indicate that a tortoise was lost.

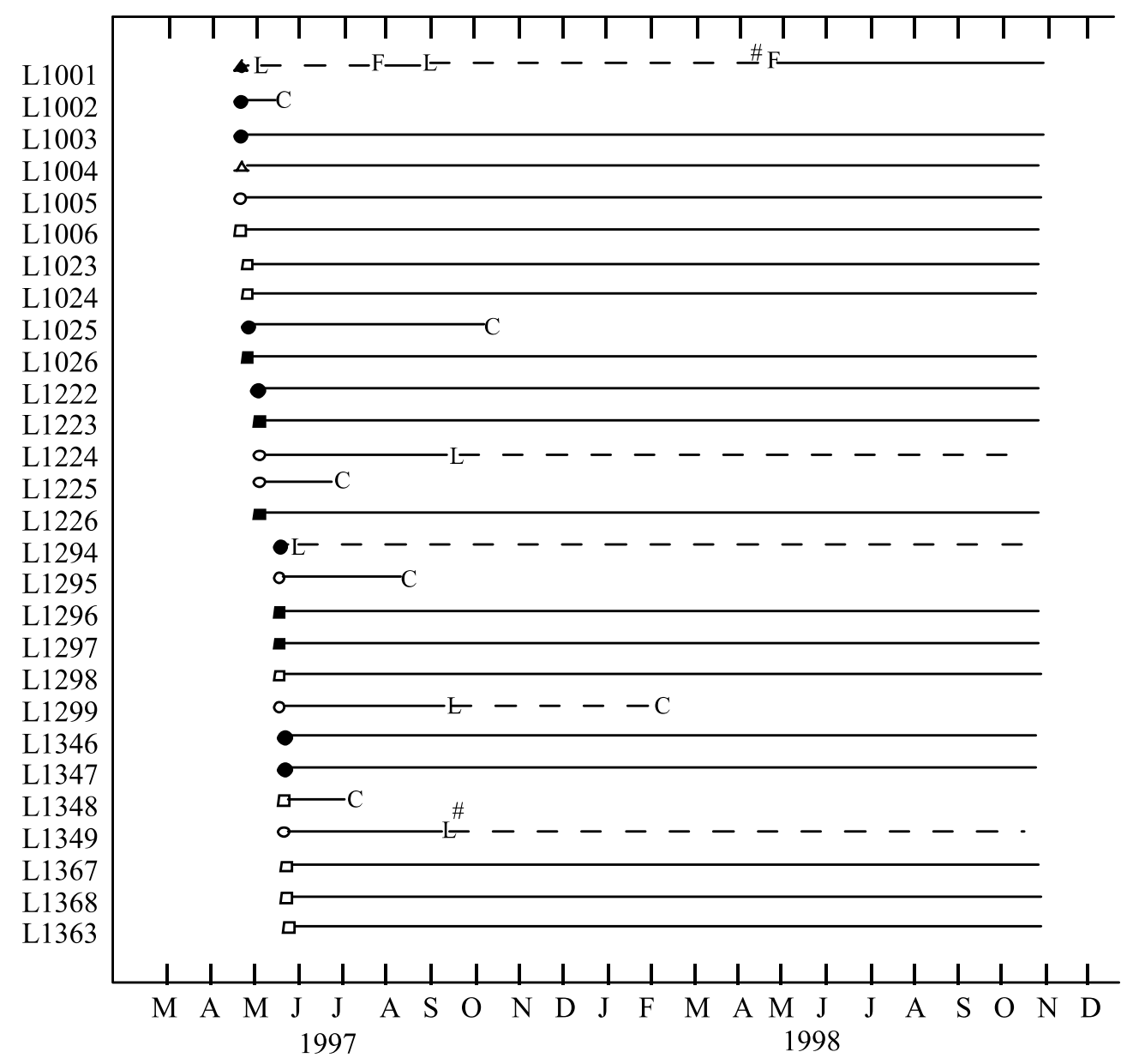




\section{R E F E R E N C E S}

Berry, K.H., 1972. Desert Tortoise relocation project: status report for 1971. Contract F-9353. State of California, Division of Highways, Desert Tortoise Relocation Project.

Berry, K.H., 1974. Desert Tortoise relocation project: status report for 1972. Contract F-9353. State of California, Division of Highways, Desert Tortoise Relocation Project.

Berry, K.H., 1975. Desert Tortoise relocation project: status report for 1974. Contract F-9353. State of California, Division of Highways, Desert Tortoise Relocation Project.

Berry, K.H., 1986. Desert Tortoise (Gopherus agassizii) relocation: implications of social behavior and movements. Herpetologica 42, 113-125.

Berry, K.H., Spangenberg, E.K., Homer, B.L., Jacobson, E.R., 2002. Deaths of Desert Tortoises following periods of drought and research manipulation. Chelonian Conservation and Biology 4, 436-448.

Brown, M.B., Schumacher, I.M., Klein, P.A., Harris, K., Correll, T., Jacobson, E.R., 1994. Mycoplasma agassizii causes upper respiratory tract disease in the Desert Tortoise. Infection and Immunity 62, 4580-4586.

Burke, R.L., 1991. Relocations, repatriations, and translocations of amphibians and reptiles: taking a broader view. Herpetologica 47, 350-357.

Burt, W.H., 1943. Territoriality and home range concepts as applied to mammals. Journal of Mammalogy 24, 346-352.

Bury, R.B., Esque, T.C., Corn, P.S., 1988. Conservation of Desert Tortoises (Gopherus agassizii): genetics and protection of isolated populations. Proceedings of the Desert Tortoise Council 1987-1991 Symposia, pp. 59-66.

Cagle, F.R., 1939. A system of marking turtles for future identification. Copeia 1939, 170-173.

Cook, J.C., 1983. Rehabilitation of the Desert Tortoise (Gopherus agassizii). MS Thesis, California State Polytechnic University, Pomona.

Cook, J.C., Weber, A.E., Stewart, G.R., 1978. Survival of captive tortoises released in California. In: Proceedings of the Desert Tortoise Council 1977 Symposium, pp. 130-135.

Cook, R.P., 2004. Dispersal, home range establishment, survival, and reproduction of translocated Eastern Box Turtles, Terrapene c. carolina. Applied Herpetology 1, 197-228.

Dantzler, W.H., Schmidt-Nielson, B., 1966. Excretion in freshwater turtle (Pseudemys scripts) and Desert Tortoise (Gopherus agassizii). American Journal of Physiology 210, 198-210.

Dodd Jr., C.K., Seigel, R.A., 1991. Relocation, repatriation, and translocation of amphibians and reptiles: are they conservation strategies that work? Herpetologica 47, 336-350.

Fischer, J., Lindenmayer, D.B., 2000. An assessment of the published results of animal relocations. Biological Conservation 96, 1-11.

Gorelow, A.S., 2005. Climate of Las Vegas, Nevada. National Oceanic and Atmospheric Administration Technical Memorandum NWS WR-271.

Griffith, B., Scott, J.M., Carpenter, J.W., Reed, C., 1989. Translocations as a species conservation tool: status and strategy. Science 245, 447-480.

Hoff, K.v.S., Marlow, R.W., 2002. Impacts of vehicle road traffic on Desert Tortoise populations with consideration of conservation of tortoise habitats in southern Nevada. Chelonian Conservation and Biology 4, 449-456.

Hooge, P.N., Eichenlaub, B., 1997. Animal movement extension to ArcView ver. 1.1. Alaska Biological Science Center, US Geological Survey, Anchorage, AK, USA.

Jacobson, E.R., Gaskin, J.M., Brown, M.B., Harris, R.K., Gardiner, C.H., LaPointe, J.L., Adams, H.P., Reggiardo, C., 1991. Chronic upper respiratory tract disease of free-ranging Desert
Tortoises (Xerobates agassizii). Journal of Wildlife Diseases 27, 296-316.

Marlow, R.W., Tollestrup, K., 1982. Mining and exploitation of natural mineral deposits by the Desert Tortoise, Gopherus agassizii. Animal Behaviour 30, 475-478.

McGinnis, S.M., Voigt, W.G., 1971. Thermoregulation in the Desert Tortoise, Gopherus agassizii. Comparative Biochemistry and Physiology 40, 119-126.

Medica, P.A., Bury, R.B., Turner, F.B., 1975. Growth of the Desert Tortoise (Gopherus agassizii) in Nevada. Copeia, 639-643.

Miller, L., 1932. Notes on the Desert Tortoise (Testudo agassizii). Transactions of the San Diego Society of Natural History 7, 189-202.

Minnich, J.E., 1977. Adaptive responses in the water and electrolyte budgets of native and captive Desert Tortoises, Gopherus agassizii, to chronic drought. In: Proceedings of the Desert Tortoise Council 1977 Symposium, pp. 102-129.

Naegle, S.R., 1976. Physiological responses of the Desert Tortoise, Gopherus agassizii. MS Thesis, University of Nevada, Las Vegas.

Nagy, K.A., Medica, P.A., 1986. Physiological ecology of Desert Tortoises in southern Nevada. Herpetologica 42, 73-92.

Nussear, K.E., 2004. Mechanistic investigation of the distributional limits of the Desert Tortoise Gopherus agassizii. Ph.D. dissertation, University of Nevada, Reno.

O'Connor, M.P., Zimmerman, L.C., Ruby, D.E., Bulova, S.J., Spotila, J.R., 1994. Home range size and movements by Desert Tortoises, Gopherus agassizii, in the eastern Mojave Desert. Hepetological Monographs 8, 60-71.

Oftedal, O.T., 2002. Nutritional ecology of the Desert Tortoise in the Mohave and Sonoran deserts. In: Van Devender, T.R. (Ed.), The Sonoran Desert Tortoise: Natural History, Biology, and Conservation. The University of Arizona Press and The Arizona-Sonora Desert Museum, Tucson, Arizona, pp. 194-241.

Peterson, C.C., 1994. Different rates and causes of high mortality in two populations of the threatened Desert Tortoise Gopherus agassizii. Biological Conservation 70, 101-108.

Peterson, C.C., 1996a. Anhomeostasis: seasonal water and solute relations in two populations of the Desert Tortoise (Gopherus agassizii) during chronic drought. Physiological Zoology 69, 1324-1358.

Peterson, C.C., 1996b. Ecological energetics of the Desert Tortoise (Gopherus agassizii): effects of rainfall and drought. Ecology 77, 1831-1844.

Rowlands, P.G., 1995. Regional bioclimatology of the California desert. In: Latting, J., Rowlands, P.G. (Eds.), The California Desert: an Introduction to Natural Resources and Man's Impact. June Latting Books, Riverside, CA, pp. 95-134.

Ruby, D.E., Zimmerman, L.C., Bulova, S.J., Salice, C.J., O'Connor, M.P., Spotila, J.R., 1994. Behavioral responses and time allocation differences in Desert Tortoises exposed to environmental stress in semi-natural enclosures. Herpetological Monographs 8, 27-44.

Science Applications International Corporation [SAIC], 1993. American Honda Desert Tortoise relocation project: final report. On file at: US Fish and Wildlife Service, Portland Regional Office. Permit PPT \#746049.

Schmidt-Nielsen, K., Bentley, P.J., 1966. Desert Tortoise Gopherus agassizii: cutaneous water loss. Science 154, 911.

Seigel, R.A., Dodd Jr., C.K., 2002. Translocations of Amphibians: proven management method or experimental technique? Conservation Biology 16, 552-554.

Soderquist, T.R., 1994. The importance of hypothesis testing in reintroduction biology: examples from the reintroduction of the carnivorous marsupial Phascogale tapoatafa. In: Serena, M. (Ed.), Reintroduction Biology of Australian and New Zealand Fauna. Surrey Beatty and Sons, Chipping Norton, pp. 159-164.

St. Amant, J.A., Hoover, F., 1978. Progress report on the experimental rehabilitation of captive Desert Tortoises. In: 
Proceedings of the Desert Tortoise Council 1978 Symposium, pp. 23-29.

Sullivan, B.K., Kwiatkowski, M.A., Schuett, G.W., 2004. Translocation of urban Gila Monsters: a problematic conservation tool. Biological Conservation 117, 235-242.

Tracy, C.R., 1982. Biophysical modeling in reptilian physiology and ecology. In: Gans, C., Pough, F.H. (Eds.), Biology of the Reptilia, vol. 12. Academic Press, London, pp. 275-321.

Tracy, C.R., 1992. Pertinent points on energy, nutrient, and water resource ecology of Desert Tortoises. Unpublished report prepared for The Desert Tortoise Recovery Team.

Tuberville, T.D., Clark, E.E., Buhlmann, K.A., Gibbons, J.W., 2005. Translocation as a conservation tool: site fidelity and movement of repatriated Gopher Tortoises (Gopherus polyphemus). Animal Conservation 8, 349-358.
Turner, R.M., 1982. Mohave desertscrub. In: Brown, D.E. (Ed.), Biotic Communities of the American Southwest - United States and Mexico. Desert Plants 4, 157-168.

US Fish and Wildlife Service [USFWS], 1990. Endangered and threatened wildlife and plants; determination of threatened status of the Mojave population of the Desert Tortoise. Federal Register 55, 12178-12191.

US Fish and Wildlife Service [USFWS], 1994. Desert Tortoise (Mojave population) recovery plan. US Fish and Wildlife Service, Portland, Oregon, 73 pp + appendices.

Wikelski, M., Thom, C., 2000. Marine iguanas shrink to survive El Niño. Nature 403, 37-38.

Woodbury, A.M., Hardy, R., 1948. Studies of the Desert Tortoise, Gopherus agassizii. Ecological Monographs 18, 145-200. 